\section{BRAZIULIAN JOURNAL}

OF MEDICAL AND BIOLOGICAL RESFARCH

www.bjournal.com.br
ISSN 0100-879X

Volume 43 (10) 914-1009 October 2010

BIOMEDICAL SCIENCES

AND

CLINICAL INVESTIGATION

Braz J Med Biol Res, October 2010, Volume 43(10) 914-919

doi: 10.1590/S0100-879X2010007500090

The neurobiology of infant maternal odor learning

C. Raineki, A. Pickenhagen, T.L. Roth, D.M. Babstock, J.H. McLean, C.W. Harley, A.B. Lucion and R.M. Sullivan

The Brazilian Journal of Medical and Biological Research is partially financed by
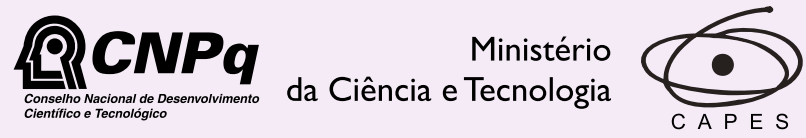

Ministério da Educação

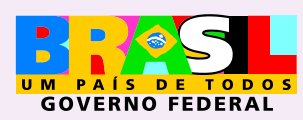

DTAPESP

Institutional Sponsors
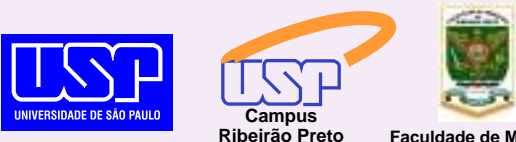

Ф SHIMADZU

GE Healthcare
Hotsite of proteomics metabolomics developped by:

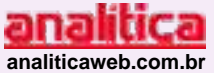

Thermo
SCIEN TIFIC 


\title{
The neurobiology of infant maternal odor learning
}

\author{
C. Raineki $1,2,3,4,5$, A. Pickenhagen ${ }^{1,2,3}$, T.L. Roth ${ }^{4,6}$, D.M. Babstock ${ }^{7}$, \\ J.H. McLean ${ }^{8}$, C.W. Harley ${ }^{7}$, A.B. Lucion ${ }^{5}$ and R.M. Sullivan ${ }^{1,2,3,4}$ \\ ${ }^{1}$ Emotional Brain Institute, Nathan Kline Institute for Psychiatric Research, Orangeburg, NY, USA \\ ${ }^{2}$ Child and Adolescent Psychiatry, New York University School of Medicine, New York, NY, USA \\ ${ }^{3}$ Center for Neural Science, New York University, New York, NY, USA \\ ${ }^{4}$ Department of Zoology, University of Oklahoma, Norman, OK, USA \\ ${ }^{5}$ Departamento de Fisiologia, Instituto de Ciências Básicas da Saúde, \\ Universidade Federal do Rio Grande do Sul, Porto Alegre, RS, Brasil \\ ${ }^{6}$ Department of Psychology, University of Delaware, Newark, DE, USA \\ ${ }^{7}$ Department of Psychology, ${ }^{8}$ Division of BioMedical Sciences, Memorial University of Newfoundland, \\ St. John's, Newfoundland, Canada
}

\begin{abstract}
Infant rats must learn to identify their mother's diet-dependent odor. Once learned, maternal odor controls pups' approach to the mother, their social behavior and nipple attachment. Here we present a review of the research from four different laboratories, which suggests that neural and behavioral responses to the natural maternal odor and neonatal learned odors are similar. Together, these data indicate that pups have a unique learning circuit relying on the olfactory bulb for neural plasticity and on the hyperfunctioning noradrenergic locus coeruleus flooding the olfactory bulb with norepinephrine to support the neural changes. Another important factor making this system unique is the inability of the amygdala to become incorporated into the infant learning circuit. Thus, infant rats appear to be primed in early life to learn odors that will evoke approach responses supporting attachment to the caregiver.
\end{abstract}

Key words: Maternal odor; Olfactory bulb; Norepinephrine; Attachment; Locus coeruleus; Amygdala

\section{Introduction}

Rapid learning for early life attachment to the caregiver has been demonstrated in many species, including humans, rodents, and avian species. The most prominent example of this early life learning was shown in avian species and was termed imprinting (1-3). Imprinting in chicks is generally considered an innate process with a biological system designed for proximity seeking of the caregiver by the altricial animal (4). However, equally important is the need for the infant to identify and learn who or what to approach (4). The interplay between the biological predisposition of proximity seeking and the plasticity of learning who/ what to follow was dramatically demonstrated by goslings learning to follow Lorenz rather than a mother goose (2). While imprinting in chicks appears to be all-or-none and irreversible (2), attachment learning in mammals seems more malleable. Human infants rapidly learn the mother's odor, voice and touch during the perinatal period, and attachment is specific to a caregiver. However, human infants can form attachments to more than one caregiver and throughout early life $(5,6)$. Thus, while attachment learning appears to be widespread throughout altricial species, specific characteristics of attachment learning vary with the ecological needs of the altricial animal.

This review will focus on the neurobiology of attachment learning in infant rats, and the results described therein suggest that neurobehavioral responses to the natural maternal odor and neonatal learned odors are very similar.

\section{Attachment learning in infant rats}

Attachment learning occurs in rat pups, although it is primarily confined to odor learning since pups do not see or hear until after the second week of life. Specifically, maternal odor controls rat pups' interactions with the mother, including approach responses, social behavior and nipple attachment (Figure 1) $(7,8)$. While maternal

Correspondence: C. Raineki, Emotional Brain Institute, Nathan S. Kline Institute for Psychiatric Research, Child and Adolescent Psychiatry, NYU School of Medicine, 140 Old Orangeburg Road, Orangeburg, NY 10962, USA. Fax: +1-845-398-2193. E-mail: craineki@nki.rfmh.org

Received July 13, 2010. Accepted August 24, 2010. Available online September 10, 2010. Published October 18, 2010. 
odor was initially viewed as a pheromone, it is now clear that it is learned prenatally, reinforced both during the birth process and repeatedly throughout the postnatal period, presumably due to the maternal diet continuously altering the maternal odor (7-10). While some risk is associated with requiring olfactory learning for survival-dependent behaviors related to attachment, prenatal odor learning of the mother's amniotic fluid (mothers spread the amniotic fluid on their ventrum during the birth process) and rapid postnatal learning appear to provide pups with a system that ensures rapid and robust maternal odor learning. This robust and rapid neonatal learning system seems to be designed to make sure that this learning will occur by the simple contiguous pairing of an odor and sensory stimulation from the mother. Thus, maternal licking of pups during the birth process reinforces the learning of the amniotic fluid and also conditions pups to novel postnatal maternal odors. This postnatal learning of maternal odor continues throughout most of the preweanling period, which is critical since the maternal odor is diet-dependent (10). The limited sensory (vision and audition emerge around 2 weeks) and motor (walking emerges around 10 days of age) abilities of rat pups also appear to limit pups' exposures to odors outside the nest.

\section{An artificial odor can become a maternal odor by applying it to the mother during mother-infant interactions}

A novel odor (i.e., peppermint or citral) applied to the mother and experienced by pups during mother-infant interactions acquires the properties of a maternal odor (11). Indeed, this new maternal odor now elicits approach behaviors and supports nipple attachment, similar to a natural maternal odor (10). Furthermore, suppressing maternal odor (via a special diet, 10) and applying a novel odor to the mother throughout preweanling life causes pups to show a preference for this odor and supports pups' nipple attachment to the mother, while the suppressed maternal odor fails to support these behaviors (11).

\section{The maternal odor can also be learned through classical conditioning}

Removing pups from the nest and performing controlled classical conditioning have added to our understanding of the learning processes that appears to occur naturally in the nest $(7,8,12-16)$. Exposing pups to a novel odor while stroking them with an artist brush (to mimic maternal licking of pups) results in a robust odor preference (Figure 1) $(8,14,17)$. Most importantly, the conditioned odor acquires the qualities of the maternal odor, with the power to control pups' social attachment behavior (Figure 1); (7,8). Specifically, the odor-stroke conditioned odor induces nipple attachment in the presence of an anesthetized mother previously washed to remove the natural maternal odor.

Not surprisingly, rat pups exhibit exquisite and robust classical conditioning abilities that appear to conform to the basic laws of learning even at birth (18). However, this early life learning shows unique characteristics that enhance learning approach responses to an odor while attenuating avoidance/aversions to other odors. For example, exposing the infant rat to an odor later to be used in conditioning (latent inhibition), enhances pup learning; conversely, presenting the odor explicitly unpaired with the reward (learned irrelevance) does not appear to affect pup learning. These procedures have profound effects on adult learning (18-21). Furthermore, while sequential presentations of stimuli enhance sensory associations in adults, simultaneous presentations are optimal in young pups (22). Thus, pups appear to have a broadly defined odor learning system that increases the probability of learning to prefer odors and presumably increases pups' proximity seeking behavior of the mother.

\section{Attachment neural circuitry learning in infant rats}

Infant attachment odor learning, natural maternal odor as well as classical conditioning are supported by a unique neural framework; brain areas important for adult learning, such as the amygdala, hippocampus and frontal cortex, are still developing and are only partially functional $(15,16,23-26)$. The neural activation of the olfactory bulb and locus coeruleus and the absence of amygdala are the major events in the infant odor attachment learning and are discussed below.

\section{Olfactory bulb neural response to the learned odor}

Pups show robust olfactory bulb responses to maternal odor. In fact, learning-induced anatomical and physiological changes within the olfactory bulb have been documented to support approach responses in infant rats (27-30). These olfactory bulb changes, as measured through increased cFos expression (8,31) and 2-deoxy-d-glucose (2-DG) uptake (11), occur in response to the natural maternal odor or to an artificial maternal odor. Moreover, rapid olfactory classical conditioning results in robust olfactory bulb activation, similar to that observed in response to natural maternal odor or to an odor placed on the mother in the nest $(8,11,28,32)$. The olfactory bulb neural changes are sufficient and necessary to support pups' approach and odor-guided interactions with the mother $(8,31,33-36)$.

The molecular cascade of the learned natural or artificial maternal odor begins with norepinephrine binding to its receptor ( $\beta$-adrenoceptor) on olfactory bulb mitral cells. Consequently, norepinephrine binding induces the production of increased amounts of cAMP, permitting the catalytic 

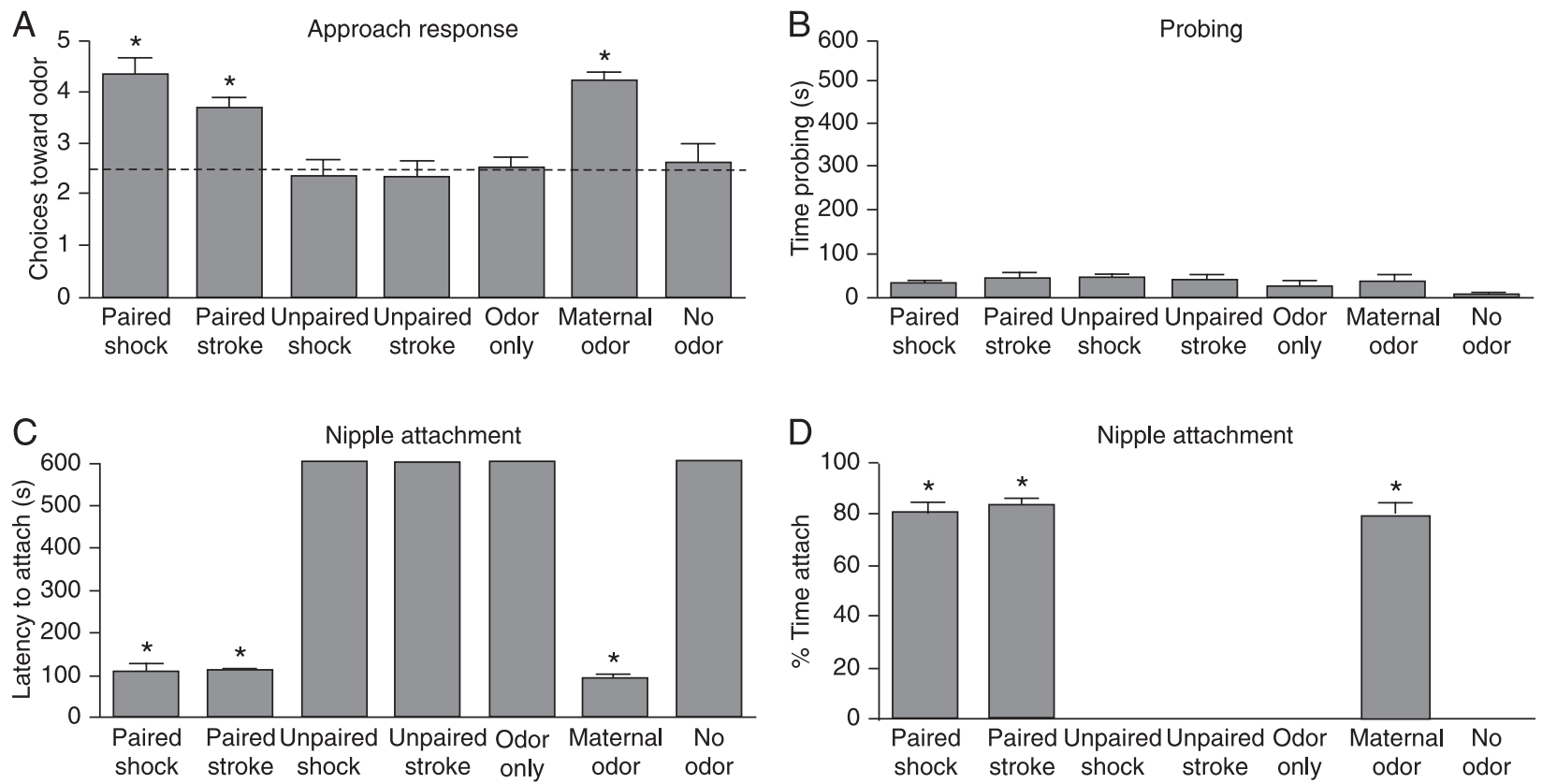

Figure 1. During early life pups approach (Y-maze) the naturally learned maternal odor or the experimentally learned attachment odor produced by pairing a novel odor (i.e., peppermint) with either stroking or a $0.5-\mathrm{mA}$ shock (A). The natural maternal odor, as well as the odor previously paired with either stroke or shock, support social interactions with the mother (B-D). If the natural maternal odor is removed, pups will show little interactions with the mother. However, an air stream of either maternal odor or the odor previously paired with stroke or shock enhances interactions with the mother, including nipple attachment. Figure reproduced from Ref. 8, with permission from Elsevier 2010. * $\mathrm{P}<0.05$ between groups (one-way ANOVA followed by the Fisher test).

subunit of protein kinase A to translocate to the nucleus. In the nucleus, protein kinase A will phosphorylate the cAMP response element binding protein (CREB) at the Ser-133 site $(17,30,37,38)$. Phosphorylated CREB (pCREB), in turn, can activate the transcription of immediate-early genes. The protein products of the immediate-early genes are transcription factors that go on to activate the transcription of late response genes that allow the formation of long-tem memory.

\section{Locus coeruleus norepinephrine is required for the olfactory bulb learning changes}

The olfactory bulb neural changes appear to depend on the contiguous presentation of odor and norepinephrine from the locus coeruleus (LC). The modified olfactory bulb response is seen during expression and has been measured by a myriad of techniques assessing neural functioning (c-Fos, 2-DG, modified single-unit response patterns of mitral/tufted cells and olfactory bulb anatomical changes) $(28,39,40)$.

The LC is the sole source of the olfactory bulb's norepinephrine $(41,42)$ and norepinephrine is both necessary and sufficient for olfactory conditioning in neonatal pups $(33,35,36,38,43-45)$. The role of norepinephrine in learning changes as pups mature, at which time norepinephrine plays more of a modulatory role of enhancing or attenuating memories $(46,47)$.

While the pup's LC is not completely mature, it is also not simply an immature version of the adult LC. Indeed, the infant LC has unique characteristics that result in an enhanced response to environmental stimuli, such as tactile stimulation mimicking maternal licking (48). First, the infant LC is more responsive to sensory stimuli than an adult LC. Secondly, the adult LC habituates after repeated presentation of the stimuli (49), whereas the infant LC fails to exhibit habituation $(50,51)$. Finally, a 1 -s presentation of tactile stimulation is likely to cause a few ms response in the adult LC, while a 20-30-s response is observed in the infant LC $(50,51)$. Together, these results indicate that the infant rat's olfactory bulb receives a uniquely large amount of norepinephrine for a more extended period of time from the LC compared with adult LC.

The development into a more adult-like LC occurs around postnatal day 10 , when the amount of norepinephrine released into the olfactory bulb is reduced. One of the principal changes in infant LC neurons is the functional development of the $\alpha 2$ inhibitory autoreceptors, responsible for the termination of the LC's excitatory response to stimuli. Moreover, the function of LC excitatory $\alpha 1$ autoreceptors becomes limited at this time and no longer extends the LC's response to sensory stimuli $(50,51)$. 


\section{Attenuated amygdala and aversion learning may help prevent pups from learning to avoid the maternal odor}

During the first 10 days of life rat pups exhibit attenuated aversion learning and pairing an odor with pain (i.e., 0.5$\mathrm{mA}$ shock or tailpinch) results in a learned odor preference (Figure 1). Learning to prefer an odor after it is paired with aversive stimuli (moderate shock and tailpinch) occurs in spite of a functional pain system as moderate shock elicits escape in neonatal pups and threshold to shock does not appear to change developmentally $(12,16,31,52)$, although the pain system continues to develop $(16,53,54)$. Observations of mother-pup interactions within the nest illustrate that the mother occasionally hurts pups during normal interactions, such as stepping on pups when she enters or leaves the nest. Considering the necessity of pups learning a preference to their mother's odor for nipple attachment and other related attachment behaviors, it is certainly beneficial to pups not to learn an aversion to their mother's odor or inhibit approach responses to nest odors. In fact, as in odor-stroke conditioning, the odor paired with shock also controls pups' social attachment behaviors with mothers by promoting nipple attachment when the conditioned odor is present (Figure 1).

The assessment of pups' attenuated aversion learning began with the amygdala because of its strong association with odor-shock fear conditioning in adulthood $(55,56)$. Our assessment of the amygdala, using 2-DG uptake (Figure 2) or c-Fos, suggested it did not participate in odor-shock conditioning during the first 10 days of life $(8,13,16,31)$.
The lack of amygdala activation in odor-shock conditioning has recently been verified using $\mathrm{PCREB}$ immunohistochemistry (Figure 2). Moreover, temporarily suppressing amygdala function with muscimol does not influence infant rats' odor-0.5-mA shock learning until the emergence of fear conditioning around postnatal day 10 (57). In fact, the lack of amygdala plasticity during infancy may play a leading role not only in the absence of fear learning, but also in the limited passive and active avoidance as well as inhibitory conditioning - behaviors critically dependent on the amygdala (58).

It is nevertheless important to note that infant rats are capable of learning odor aversions. Specifically, odor/ taste-malaise ( $\mathrm{LiCl}$ or $>1 \mathrm{~mA}$ shock) learning can produce odor aversions, even in the fetal rat $(15,52)$, although this malaise learning is greatly attenuated if pups are nursing during conditioning $(59,60)$. This malaise conditioning does not appear to incorporate the amygdala until weaning, suggesting pain and malaise learning are using different, albeit overlapping, neural circuits $(15,60)$.

\section{Ecological significance}

For altricial animals such as rats, attachment learning is critical for survival. In fact, pups' survival is dependent on learning this maternal odor preference/approach. Besides being attractive for the pups, the maternal odor also organizes pups' social behavior ensuring that pups will nipple attach and receive care and necessary warmth. Evolutionary pressures may have selected for a unique attachment neural circuitry to ensure pups' rapid attachment to the caregiver.

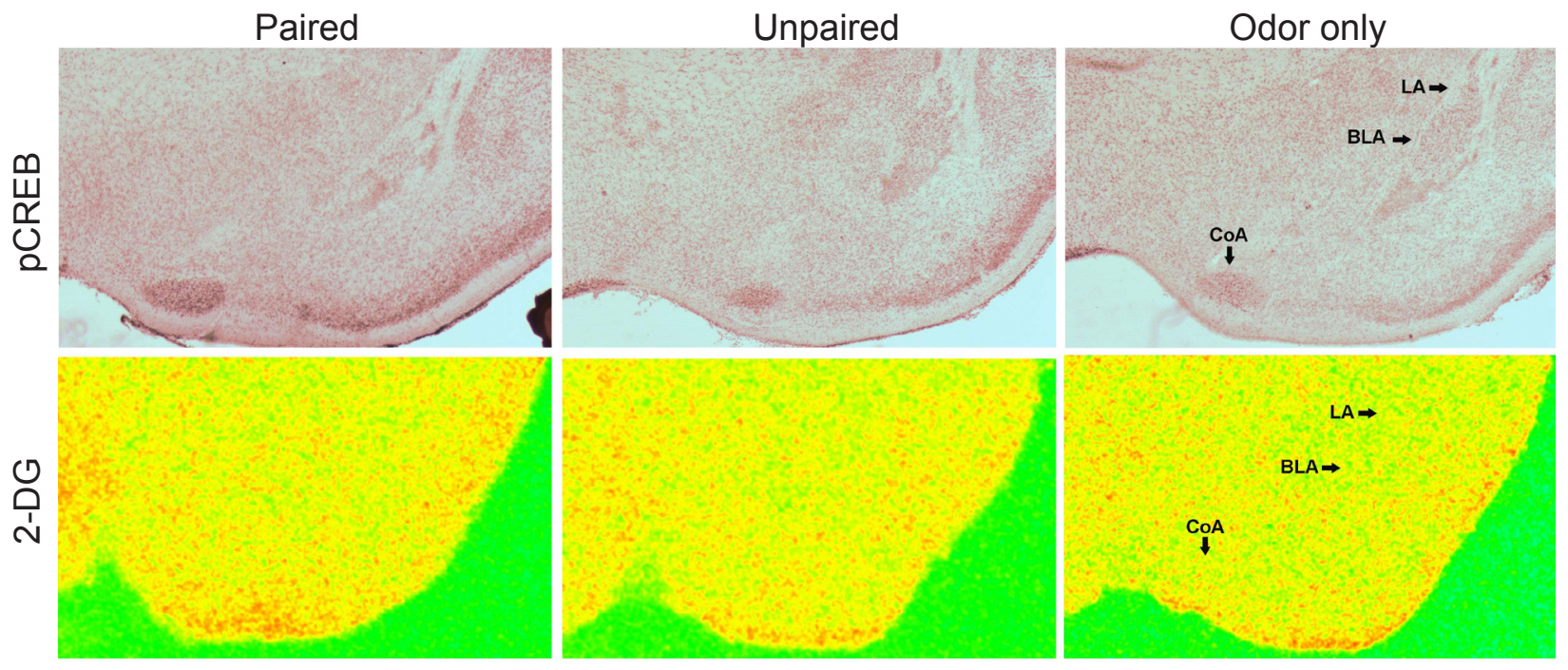

Figure 2. During early life (postnatal day 8), pairing an odor with a $0.5-\mathrm{mA}$ shock does not produce a change in pCREB expression (top) or 2-deoxy-d-glucose (2-DG) uptake (bottom) in the lateral (LA) and basolateral (BLA) amygdala. The expression of phosphorylated cAMP response element binding protein (pCREB) in the cortical amygdala (CoA), a component of the olfactory cortex, appears to be heightened by odor exposure. 
The infant circuitry is not only unique because of the absence or immaturity of certain brain structures, such as the amygdala, but also because of the unique characteristics of other brain areas, such as the olfactory bulb encoding learning and the LC's hyperfunctionality.

In summary, this brief review comparing the behavioral and neural responses of pups to both natural and learned maternal odors suggests pups are predisposed to learn proximity seeking behaviors to the caregiver. These data also support behavioral results suggesting that novel neonatal and natural maternal odors use similar neural structures to acquire their control over pups' behavior.

\section{Acknowledgments}

Research supported by NIH DC009910 and MH091451, NSF IOB-0850527 and IOB-0544406 grants to R.M. Sullivan, by CAPES, CNPq and FAPESP grants to A.B. Lucion, by an NSERC 9791 grant to C.W. Harley, and by a CIHR MOP53761 grant to J.H. McLean and C.W. Harley.

\section{References}

1. Hess E. Ethology: An approach to the complete analysis of behavior. In: Brown R, Galanter E, Hess E, Mendler G (Editors), New directions in psychology. New York: Holt, Rinehart and Winston; 1962. p 159-199.

2. Lorenz KZ. Companions as factors in the bird's environment. In: Lorenz KZ (Editor), Studies in animal and human behavior. Cambridge: Harvard University Press; 1970.

3. Salzen E. Imprinting and environmental learning. In: Aronson LR, Tobach E, Lehrman DS, Rosenblatt JS (Editors), Development and evolution of behavior. San Francisco: W.H. Freeman; 1970. p 158-178.

4. Bolhuis JJ, Honey RC. Imprinting, learning and development: from behaviour to brain and back. Trends Neurosci 1998; 21: 306-311.

5. Decasper AJ, Fifer WP. Of human bonding: newborns prefer their mothers' voices. Science 1980; 208: 1174-1176.

6. Sullivan RM, Toubas P. Clinical usefulness of maternal odor in newborns: soothing and feeding preparatory responses. Biol Neonate 1998; 74: 402-408.

7. Pedersen PE, Williams CL, Blass EM. Activation and odor conditioning of suckling behavior in 3-day-old albino rats. $J$ Exp Psychol Anim Behav Process 1982; 8: 329-341.

8. Raineki C, Moriceau S, Sullivan RM. Developing a neurobehavioral animal model of infant attachment to an abusive caregiver. Biol Psychiatry 2010; 67: 1137-1145.

9. Hofer MA, Shair H, Singh P. Evidence that maternal ventral skin substances promote suckling in infant rats. Physiol Behav 1976; 17: 131-136.

10. Leon M. Neuroethology of olfactory preference development. J Neurobiol 1992; 23: 1557-1573.

11. Sullivan RM, Wilson DA, Wong R, Correa A, Leon M. Modified behavioral and olfactory bulb responses to maternal odors in preweanling rats. Brain Res Dev Brain Res 1990; 53: 243-247.

12. Camp LL, Rudy JW. Changes in the categorization of appetitive and aversive events during postnatal development of the rat. Dev Psychobiol 1988; 21: 25-42.

13. Johanson IB, Teicher MH. Classical conditioning of an odor preference in 3-day-old rats. Behav Neural Biol 1980; 29: 132-136.

14. McLean JH, Darby-King A, Sullivan RM, King SR. Serotonergic influence on olfactory learning in the neonate rat. Behav Neural Biol 1993; 60: 152-162.

15. Raineki C, Shionoya K, Sander K, Sullivan RM. Ontogeny of odor-LiCl vs. odor-shock learning: similar behaviors but divergent ages of functional amygdala emergence. Learn
Mem 2009; 16: 114-121.

16. Sullivan RM, Landers M, Yeaman B, Wilson DA. Good memories of bad events in infancy. Nature 2000; 407: 3839.

17. Yuan Q, Harley CW, Darby-King A, Neve RL, McLean JH. Early odor preference learning in the rat: bidirectional effects of cAMP response element-binding protein (CREB) and mutant CREB support a causal role for phosphorylated CREB. J Neurosci 2003; 23: 4760-4765.

18. Spear NE, Rudy JW. Tests of the ontogeny of learning and memory: Issues, methods, and results. In: Shair HN, Barr GA, Hofer MA (Editors), Developmental psychobiology: New methods and changing concepts. New York: Oxford University Press; 1991. p 84-113.

19. Campbell BA, Spear NE. Ontogeny of memory. Psychol Rev 1972; 79: 215-236.

20. Hoffmann H, Spear NE. Facilitation and impairment of conditioning in the preweanling rat after prior exposure to the conditioned stimulus. Anim Learn Behav 1989; 17: 63-69.

21. Stanton ME, Fox GD, Carter CS. Ontogeny of the conditioned eyeblink response in rats: acquisition or expression? Neuropharmacology 1998; 37: 623-632.

22. Barr R, Marrott H, Rovee-Collier $\mathrm{C}$. The role of sensory preconditioning in memory retrieval by preverbal infants. Learn Behav 2003; 31: 111-123.

23. Fanselow MS, Rudy JW. Convergence of experimental and developmental approaches to animal learning and memory processes. In: Carew TJ, Menzel R, Shatz CJ (Editors), Mechanistic relationships between development and learning. New York: J. Wiley \& Sons; 1998. p 15-28.

24. Rudy JW, Morledge P. Ontogeny of contextual fear conditioning in rats: implications for consolidation, infantile amnesia, and hippocampal system function. Behav Neurosci 1994; 108: 227-234.

25. Thompson JV, Sullivan RM, Wilson DA. Developmental emergence of fear learning corresponds with changes in amygdala synaptic plasticity. Brain Res 2008; 1200: 58-65.

26. Verwer RW, Van Vulpen EH, Van Uum JF. Postnatal development of amygdaloid projections to the prefrontal cortex in the rat studied with retrograde and anterograde tracers. J Comp Neurol 1996; 376: 75-96.

27. Sullivan RM, Wilson DA. The role of norepinephrine in the expression of learned olfactory neurobehavioral responses in infant rats. Psychobiology 1991; 19: 308-312.

28. Wilson DA, Sullivan RM, Leon M. Single-unit analysis of postnatal olfactory learning: modified olfactory bulb output 
response patterns to learned attractive odors. $J$ Neurosci 1987; 7: 3154-3162.

29. Woo CC, Coopersmith R, Leon M. Localized changes in olfactory bulb morphology associated with early olfactory learning. J Comp Neurol 1987; 263: 113-125.

30. Yuan Q, Harley CW, McLean JH. Mitral cell beta1 and 5-HT2A receptor colocalization and cAMP coregulation: a new model of norepinephrine-induced learning in the olfactory bulb. Learn Mem 2003; 10: 5-15.

31. Roth TL, Sullivan RM. Memory of early maltreatment: neonatal behavioral and neural correlates of maternal maltreatment within the context of classical conditioning. Biol Psychiatry 2005; 57: 823-831.

32. Johnson BA, Woo CC, Duong H, Nguyen V, Leon M. A learned odor evokes an enhanced Fos-like glomerular response in the olfactory bulb of young rats. Brain Res 1995; 699: 192-200.

33. Sullivan RM, Wilson DA, Lemon C, Gerhardt GA. Bilateral 6-OHDA lesions of the locus coeruleus impair associative olfactory learning in newborn rats. Brain Res 1994; 643: 306-309.

34. Sullivan RM, Zyzak DR, Skierkowski P, Wilson DA. The role of olfactory bulb norepinephrine in early olfactory learning. Brain Res Dev Brain Res 1992; 70: 279-282.

35. Langdon PE, Harley CW, McLean JH. Increased beta adrenoceptor activation overcomes conditioned olfactory learning deficits induced by serotonin depletion. Brain Res Dev Brain Res 1997; 102: 291-293.

36. Moriceau S, Sullivan RM. Maternal presence serves as a switch between learning fear and attraction in infancy. Nat Neurosci 2006; 9: 1004-1006.

37. McLean JH, Harley CW, Darby-King A, Yuan Q. pCREB in the neonate rat olfactory bulb is selectively and transiently increased by odor preference-conditioned training. Learn Mem 1999; 6: 608-618.

38. Yuan Q, Harley CW, Bruce JC, Darby-King A, McLean JH. Isoproterenol increases CREB phosphorylation and olfactory nerve-evoked potentials in normal and 5-HT-depleted olfactory bulbs in rat pups only at doses that produce odor preference learning. Learn Mem 2000; 7: 413-421.

39. Coopersmith R, Leon M. Enhanced neural response by adult rats to odors experienced early in life. Brain Res 1986; 371: 400-403.

40. Wilson DA, Leon M. Spatial patterns of olfactory bulb singleunit responses to learned olfactory cues in young rats. $J$ Neurophysiol 1988; 59: 1770-1782.

41. McLean JH, Shipley MT. Postnatal development of the noradrenergic projection from locus coeruleus to the olfactory bulb in the rat. $J$ Comp Neurol 1991; 304: 467-477.

42. Shipley MT, Halloran FJ, de la Torre J. Surprisingly rich projection from locus coeruleus to the olfactory bulb in the rat. Brain Res 1985; 329: 294-299.

43. Moriceau S, Sullivan RM. Unique neural circuitry for neonatal olfactory learning. J Neurosci 2004; 24: 1182-1189.
44. Rangel S, Leon M. Early odor preference training increases olfactory bulb norepinephrine. Brain Res Dev Brain Res 1995; 85: 187-191.

45. Sullivan RM, Stackenwalt G, Nasr F, Lemon C, Wilson DA. Association of an odor with activation of olfactory bulb noradrenergic beta-receptors or locus coeruleus stimulation is sufficient to produce learned approach responses to that odor in neonatal rats. Behav Neurosci 2000; 114: 957-962.

46. Ferry B, Roozendaal B, McGaugh JL. Role of norepinephrine in mediating stress hormone regulation of long-term memory storage: a critical involvement of the amygdala. Biol Psychiatry 1999; 46: 1140-1152.

47. Moffat SD, Suh EJ, Fleming AS. Noradrenergic involvement in the consolidation of maternal experience in postpartum rats. Physiol Behav 1993; 53: 805-811.

48. Nakamura S, Kimura F, Sakaguchi T. Postnatal development of electrical activity in the locus ceruleus. $J$ Neurophysiol 1987; 58: 510-524.

49. Vankov A, Herve-Minvielle A, Sara SJ. Response to novelty and its rapid habituation in locus coeruleus neurons of the freely exploring rat. Eur J Neurosci 1995; 7: 1180-1187.

50. Kimura F, Nakamura S. Locus coeruleus neurons in the neonatal rat: electrical activity and responses to sensory stimulation. Brain Res 1985; 355: 301-305.

51. Nakamura S, Salaguchi T. Development of plasticity of the locus coeruleus. A review of recent physiological and pharmacological experimentation. Prog Neurbiol 1990; 34: 505-526.

52. Haroutunian V, Campbell BA. Emergence of interoceptive and exteroceptive control of behavior in rats. Science 1979; 205: 927-929.

53. Barr GA. Ontogeny of nociception and antinociception. NIDA Res Monogr 1995; 158: 172-201.

54. Fitzgerald $\mathrm{M}$. The development of nociceptive circuits. Nat Rev Neurosci 2005; 6: 507-520.

55. Fanselow MS, Gale GD. The amygdala, fear, and memory. Ann N Y Acad Sci 2003; 985: 125-134.

56. LeDoux JE. Emotion circuits in the brain. Annu Rev Neurosci 2000; 23: 155-184.

57. Moriceau S, Wilson DA, Levine S, Sullivan RM. Dual circuitry for odor-shock conditioning during infancy: corticosterone switches between fear and attraction via amygdala. $J \mathrm{Neu}$ rosci 2006; 26: 6737-6748.

58. Collier AC, Mast J, Mayer D, Jacobs C. Approach avoidance conflict in preweanling rats: A developmental study. Anim Learn Beahav 1979; 7: 514-520.

59. Martin LT, Alberts JR. Taste aversions to mother's milk: the age-related role of nursing in acquisition and expression of a learned association. J Comp Physiol Psychol 1979; 93: 430-445.

60. Shionoya K, Moriceau S, Lunday L, Miner C, Roth TL, Sullivan RM. Development switch in neural circuitry underlying odor-malaise learning. Learn Mem 2006; 13: 801-808. 